\title{
KORPUS KALLOSUMUN DİFÜZYON AĞIRLIKLI VE KONVANSIYYONEL MANYETİK REZONANS GÖRÜNTÜLEME İLE YAŞA GÖRE DEĞERLENDİRILMESI
}

\author{
Evaluation of Corpus Callosum by Means of Diffusion-Weighted and Conventional Magnetic \\ Resonance Imaging According to the Age
}

\author{
Rabia KARASU ${ }^{1}$, Yasemin BİLGíLi ${ }^{2}$ \\ ${ }^{1}$ Istinye Devlet Hastahanesi, Radyoloji Bölümü, ISTANBUL, TÜRKIYE \\ ${ }^{2}$ Kırıkkale Üniversitesi Tıp Fakültesi, Radyoloji A.D., KIRIKKALE, TÜRKIYE
}

\begin{abstract}
Amaç: Difüzyon ağırlıklı görüntüleme, beyin dokusunun canlılı̆̆ hakkında fikir veren önemli bir yöntem olup kuvvetli manyetik alan gradientleri kullanılmaktadır. Buna bağlı olarak difüzyon ağıllıklı görüntüleme tekniği su moleküllerinin mikroskopik hareketlerindeki değişikliklerin saptanmasını mümkün kılmaktadır. Çalışmamızda, difüzyon ağırlıklı görüntüleme ile su moleküllerinin aksonlar boyunca olan hareketlerinden yararlanarak elde edilen Apparent Diffusion Coefficient (ADC) değişikliklerinin yaşa göre değişiminin değerlendirilmesi amaçlanmıştır.

Gereç ve Yöntem: Çalışmamıza dahil edilen 94 olgunun ADC haritaları üzerinden korpus kallosumun farklı bölgelerinden ADC değerleri değerlendirildi.

Bulgular: ADC değerinin minimum ve maksimum değerleri $0.589-0.819 \mathrm{~mm}^{2} / \mathrm{sn} \times 10^{-3}$, ortalama ADC değeri ise $0.735 \pm 0.043 \mathrm{~mm}^{2} / \mathrm{sn} \times 10^{-3}$ olarak bulunmuştur. Çalışmamızda yaş arttıkça, korpus kallosumun ortalama ADC değerlerinde istatistiksel olarak belirgin derecede artış bulunmuştur $(\mathrm{p}<0.01)$.

Sonuç: İlerleyen yaşla beyaz cevherdeki suyun difüzyon kabiliyetindeki artış yönündeki teorimiz, verilerimizdeki istatistiksel olarak anlamlı sonuçlarla desteklenmiştir. Yani suyun korpus kallosumda difüzyon kabiliyetinin yaş ilerledikçe arttığı saptanmıştır. Sonuç olarak, fonksiyonel bir görüntüleme yöntemi olan difüzyon ağırlıklı görüntüleme, yaşlanmaya bağlı değişiklikleri sayısal olarak da ortaya koyabilen bir yöntemdir.
\end{abstract}

Anahtar Kelimeler: Difüzyon ă̆ırlıklı görüntüleme, Apparent Diffusion Coefficient, korpus kallosum, yaş
Objective: Evaluation of corpus callosum by means of diffusionweighted and conventional magnetic resonance imaging according to the age Diffusion-weighted imaging (DWI) is a significant method that gives an idea as to the vitality of the brain tissue. DWI is affected from the movements of the patient at a minimum with its strong magnetic field gradients and is extraordinarily sensitive in reflection of the changes in the microscopic translational activities of the water molecules. Objective of our study is to evaluate by means of diffusionweighted imaging the Apparent Diffusion Coefficient (ADC) changes by aging which are obtained using the activities of the water molecules throughout axons.

Material and Methods: ADC measurement of corpus callosum at different parts has been studied in 94 patient

Results: Minimum and maximum values of the ADC value were found as $0.589-0.819 \mathrm{~mm}^{2} / \mathrm{sn} \times 10^{-3}$ while the average ADC value was found as $0.735 \pm 0.043 \mathrm{~mm}^{2} / \mathrm{sn} \times 10^{-3}$. Our study has revealed a distinctive statistical increase in the average ADC values of corpus callosum in line with aging $(\mathrm{p}<0.01)$.

Conclusion: Our theory as to the increase in the diffusion capability of the water in the white substance along with aging has been substantiated with the statistically significant results in our data. In other words, it has been detected that diffusion capability of the water in corpus callosum increases along with aging. In conclusion, it is beyond doubt that the diffusion-weighted MRI which is a new functional imaging method in clinic application will be improved even better in the years to come and can be used in a more widespread manner.

Keywords: Diffusion-weighted imaging, Apparent Diffusion Coefficient, corpus callosum, age. 


\section{GİRIŞ}

Beyin hacmi matürasyon sırasında artış gösterir. $\mathrm{Bu}$ değişikliğin en belirgin olduğu zaman ilk iki yaştır. Daha önceki çalışmalar sekiz yaşına kadar, beyinde su içeriğinde azalma ve hücre sayısında artış olduğunu göstermiştir. Yaşlanmanın etkisi ile beyaz cevherdeki selektif atrofi, gri cevherden belirgin olarak izlenmektedir. Beyaz cevherdeki atrofi, myeline liflerdeki azalmaya bağlıdır. Bu duruma ekstrasellüler mesafedeki artış da eşlik eder. Ayrıca beyaz cevherdeki kapiller duvarlar yaşla incelir ve fokal beyaz cevher kayıpları ile gliozis ortaya çıkar. Yaşlanan populasyonda konvansiyonel Manyetik Rezonans Görüntüleme (MRG) özellikleri şöyle sıralanabilir: Beyin Omurilik Sıvı (BOS) mesafesinde artış, kortikal sulkuslarda beyin atrofisi ile birlikte genişleme, serebral hemisferlerde hacim kayb1, lateral ventriküllerde genişlemeler, beyaz cevherdeki yamalı anormal intensiteler, bazal ganglionlarda (putamen ve globus pallidus) demir birikiminin neden olduğu T2 ağırlıklı incelemelerdeki hipointensitelerdir (1-3).

Beyindeki difüzyonun yapısal ve dinamik doku özelliklerini yansıttığı bilinmektedir. Difüzyon ağırlıklı görüntüleme (DAG) ile konvansiyonel yöntemlerle normal olarak değerlendirilen beyin dokusundaki yaşlanmaya bağlı değişikliklerin değerlendirilmesi ve tespiti yaşlanma sürecinin daha iy anlaşılmasında değer taşımaktadır. Yaş bağımlı normal difüzyon değerlerinin bilinmesi, hipertansif ensefalopati, obstrüktif ensefalopati gibi diffüz değişikliklerin değerlendirilmesinde önem kazanmaktadır (1).

Daha önceki bazı difüzyon MRG çalı̧̧maları ise hayatın ilk 10 yılında beyin difüzyonunun azaldığını ve bunun erişkin yaşa kadar sabit kaldığını göstermiştir (4). Beyin matürasyonundaki artışla su molekülerindeki hareketlilik ve Apparent Diffusion Coefficient (ADC) azalır. ADC'deki bu azalma birkaç faktörün etkisi ile gerçekleşir. Matür nöron ile gliadaki artı̧ ve myelin proliferasyonu nedeniyle ekstrasellüler mesafe daralır. Bir diğer neden, hidrofobik myelin membranları nedeniyle su molekül hareketinde fiziksel kısitll11k olmasıdır. Bu kisitl1lik myeline dik eksende varken, ona paralel eksenlerde yoktur (5).

Yaşlanan beyin dokusunda ortaya çıkan yapısal değişiklikler MRG tetkiki ile ayrıntılı bir biçimde gösterilmiştir, ancak yapısal değişikliğe neden olmayan mikro düzeydeki değişikliklerin saptanması konvansiyonel MRG sekansları ile mümkün olmamaktadır. DAG, konvansiyonel MRG ile tespit edilen makroskopik anatomiye ek olarak konvansiyonel yöntemlerle tespit edilemeyen hücresel düzeydeki bilgiyi sayısal olarak sunmaktadır. Çalışmamızda en büyük kommisürel fiber olan korpus kallosumdaki yaşla ortaya çıkan değişiklikler ADC değerleri üzerinde kantitatif olarak gösterilmesi hedeflenmiştir.

\section{GEREÇ VE YÖNTEM}

Çalışmaya, Kırıkkale Üniversitesi Tıp Fakültesi Radyoloji Anabilim Dalına beyin MRG tetkiki için, 2007 yılı Eylül-2008 yılı Ocak ayları arasında başvuran, 184 kişi alındı. Vakalardan MRG sonuçlarında patoloji saptananlar, nörolojik problemi olanlar, santral sinir sistemi patolojisi ve malignite öyküsü bulunanlar çalışmaya alınmadı. Ayrıca noktasal hiperintensitesi olan hastalardan, üç milimetreden büyük üçten fazla hiperintens alanı olanlar da çalışma dışı bırakıldı. Geriye kalan 94 kişinin verileri değerlendirildi.

8-75 yaş arasındaki vakaların 58'i (\%61) bayan, 36'sı (\%38) erkekti. Vaka grubumuzdaki yaygın şikayet baş ağrısı ve baş dönmesiydi.

Konvansiyonel ve Difüzyon MR incelemeleri, 1.5 Tesla MR cihazı (Intera Master, Philips Medikal Sistemleri, Cleveland, USA) ile standart kafa sarmalı kullanılarak yapıldı. Difüzyon ağırlıklı görüntülemede Philips medikal sistemlerinde bulunan Eko Planar puls (EPI) sekansı kullanıldı.

MR incelemede değerlendirmeye alınan sekanslardan, sagittal planda T1 ağırlıklı sekansın parametreleri; (596/15; TR msn/TE msn), kesit kalınlığ 5 mm, 
intersection gap 1mm, field of view (FOV) $250 \mathrm{~mm}$ ve matriks 192 x $256 \mathrm{~mm}$, sapma açısı 69․ kesit sayısı 22; sagittal planda difüzyon ağırlıklı görüntülemenin parametreleri; (3469/92; TR msn/TE msn), kesit kalınlığ1 $5 \mathrm{~mm}$, intersection gap $1 \mathrm{~mm}$, FOV $230 \mathrm{~mm}$ ve matriks 90x128 mm, sapma açıs $90^{\circ}$, kesit sayısı 22 olarak alınd1.

DAG için, EPI sekansından yararlanıldı. İlk olarak difüzyon gradiyenti uygulanmadan $\left(b=0 \mathrm{~mm}^{2} / \mathrm{sn}\right) \mathrm{T} 2$ ağırlıklı görüntüler elde edildi. Bunu takiben $b=1000$ $\mathrm{mm}^{2} / \mathrm{sn}$ değeri ile difüzyon duyarlı gradiyentler her üç yönde (x, y, z ekseninde) uygulandı ve üç gradiyentin ortalaması alınarak "trace" görüntüler elde edildi. Otomatik olarak oluşturulan ADC haritaları, ADC değerlerinin ölçümlerinde kullanıldı.

Korpus kallosum boyut ve ADC değerlerinin ölçümü için midsagittal kesitler alındı. Beyinin midsagittal planı, anterior komissür ve interhemisferik fissürün izlendiği lokalizasyon olarak belirlendi.
T1 ağırlıklı sagittal incelemelerde, midsagittal hattan, öncelikle korpus kallosum çevresi manuel olarak belirlendi ve yüzey ölçümü yapıldı (Şekil 1). Bundan sonra anteroposterior olarak korpus kallosumun en uzun olduğu yerden boyu (CCBOY), anterior ve posteriordaki bulboz kesimin en geniş yerinden genu (GENU) ile spleniumun (SPL) boyutu ölçüldü. Korpus kallosumun korpus kesiminin boyutu (KORP) ise daha önce ölçümü alınan uzun aksının ortası bulunarak, buradan kraniokaudal olarak alındı.

Sagittal plandaki difüzyon ağırlıklı görüntülerden oluşturulan ADC haritalarından ortalama $10 \pm 2 \mathrm{~mm}^{2}$ boyutundaki ROI ile korpus kallosumun rostrum, genu, korpus ve spleniumunun ADC değerleri ölçüldü (Şekil 2). Daha sonra ADC haritalarında midsagittal hattan, korpus kallosumun tamamı, çevresinin manuel olarak çizilmesiyle elde olunan ROI içine dahil edilerek ortalama ADC değerleri (ROIADC) alındı. Ölçümler sırasında ROI içerisinde BOS'un girmemesine özen gösterildi (Şekil 3).



Şekil 1. Manuel olarak belirlenen korpus kallosum çevresi ve yüzey ölçümü. 


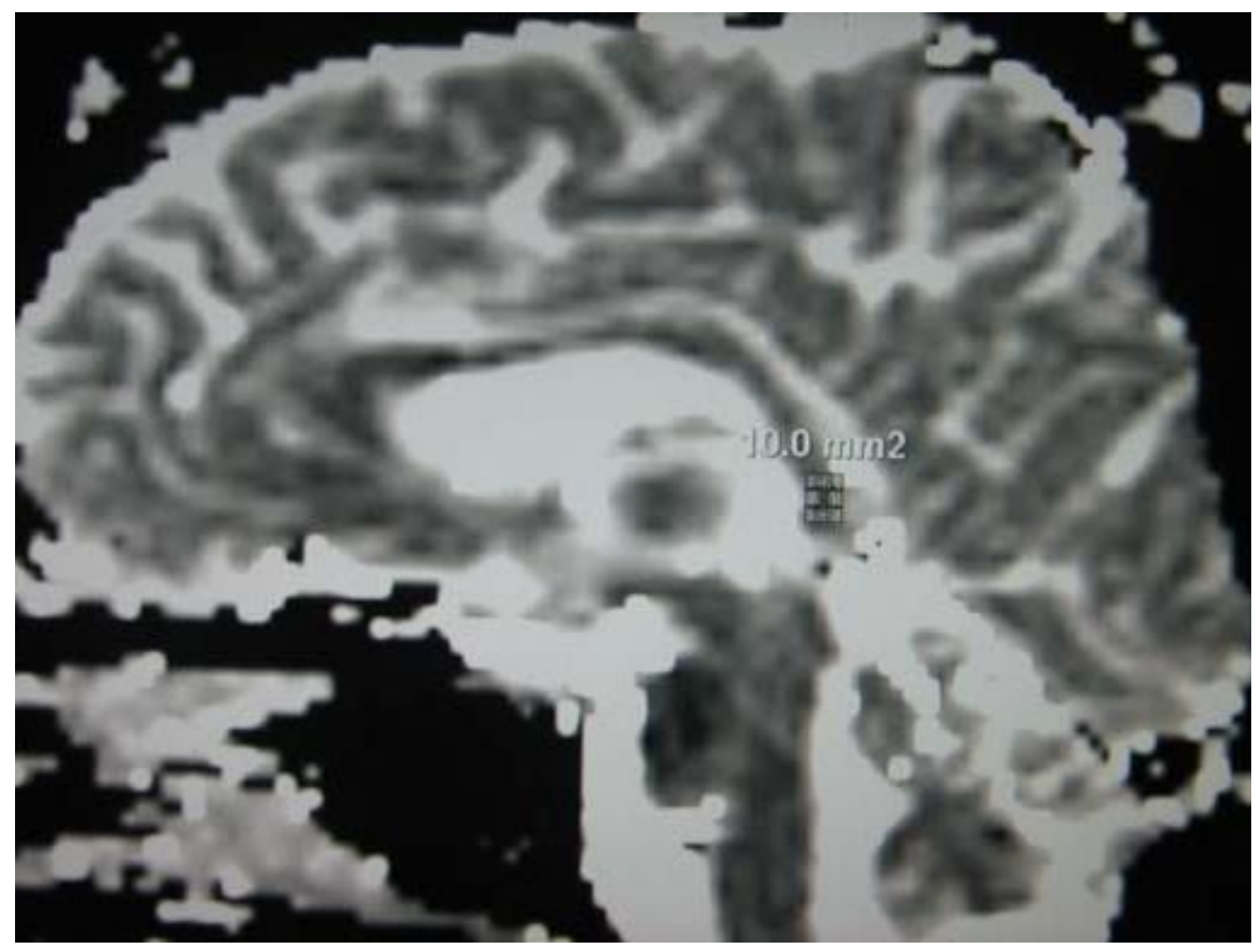

Şekil 2. Sagittal difüzyon ağırlıklı görüntülerden oluş̧urulan ADC haritasında korpus kallosumun spleniumunun ADC değerinin ölçümü.

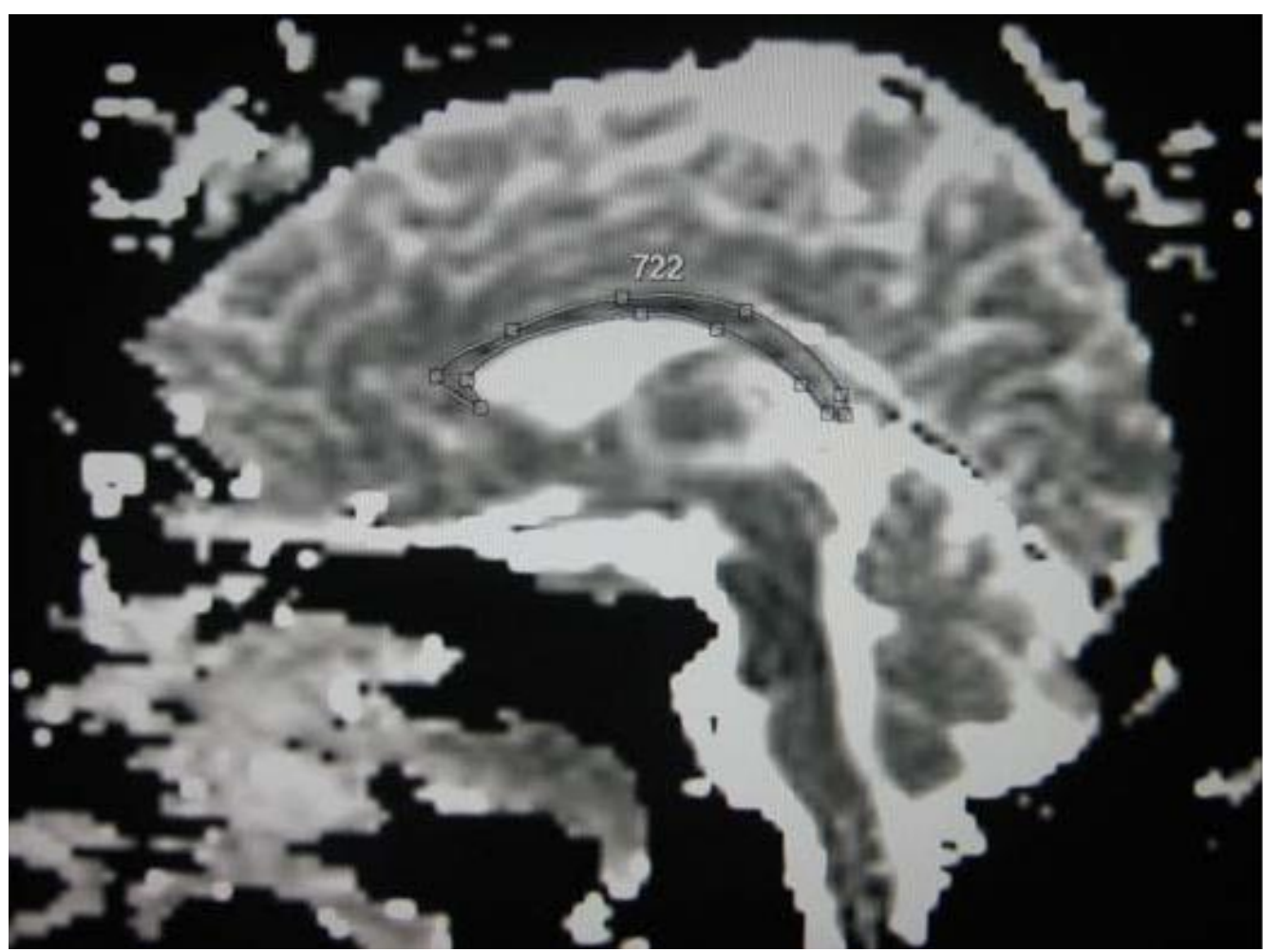

Şekil 3. Sagittal difüzyon ağıllıklı görüntüde korpus kallosumun tamamı ROI içine dahil edilerek ortalama ADC değerinin (ROIADC) ölçümü. 
Olgular, istatistiksel açıdan değerlendirilmek için olmak üzere toplam yedi yaş grubuna ayrıldı. Ayrıca bireyler, daha ileri yaş grubunun ADC değerlerini daha genç olanlarla karşılaştırabilmek için 60 yaş üzeri yaş grubu, 60 yaş ve altı yaş grubu olarak da gruplandırıldı. Verilerin analizi SPSS paket programında yapıldı. Cinsiyete göre karşılaştırma için bağımsız gruplarda $\mathrm{t}$ testi kullanıldı. Yaş ile diğer değişkenler arasındaki ilişkiyi incelerken Pearson korelasyon katsayısı hesaplandı. Tek yönlü varyans analizi (ANOVA) ile yaş grupları arasında fark olup olmadığı incelendi. Yaş gruplarına göre fark önemli bulunan iki değişken için ikili kaşılaştırmalar Tukey testi ile yapıldı. Yani hangi yaş grubu ya da gruplarının farklılığ 1 yarattığ 1 bu test ile incelendi.

Tanımlayıcı istatistikler sürekli değişkenler için ortalama \pm standart sapma, kategorik değişkenler için \%olarak verildi. $\mathrm{P}<0.05$ için sonuçlar istatistiksel olarak anlamlı kabul edildi.

$\mathrm{Bu}$ çalışma için, Kırıkkale Üniversitesi Tıp Fakültesi Etik Kurul Başkanlığı'ndan 04. 02. 2008 tarih ve 2008/017 sayılı etik kurul onayı alınmıştır.



Şekil 4. Korpus kallosumun yaş gruplarına göre ortalama ADC değerleri 


\section{BULGULAR}

Çalışmaya, Kırıkkale Üniversitesi Tıp Fakültesi Radyoloji anabilim dalına beyin MRG tetkiki için, 2007 yılı eylül-2008 yılı ocak ayları arasında başvuran 184 kişi alındı. Bunlardan 94'ünün verileri değerlendirmeye tabi tutuldu.

\section{Yaş ve Cinsiyet Gruplart}

8-75 yaş arasındaki 94 bireyin 58'i (\%61) bayan, 36's1 (\%38) erkekti. Tüm vaka grubunun yaş ortalaması $44 \pm$ 16.9 , bayanların yaş ortalaması $41.78 \pm 16.78$, erkelerin yaş ortalaması ise $36 \pm 16.69$ olarak bulundu. 60 yaş ve altında $79(\%), 61$ yaş ve üzerinde $15(\%)$ olgu vard1. Ayıca olgular dekatlara göre yedi yaş grubuna ayrıldı (Tablo 1).

Tablo 1. Yaş gruplarına göre vaka sayıları ve toplam sayıya oranları.

\begin{tabular}{ccc}
\hline Yaş grupları & Sayı & $\%$ \\
\hline$=<19$ & 8 & 8.5 \\
$20-29$ & 12 & 12.7 \\
$30-39$ & 16 & 17 \\
$40-49$ & 18 & 19.1 \\
$50-59$ & 23 & 24.5 \\
$60-69$ & 10 & 10.6 \\
$70-79$ & 7 & 7.5 \\
\hline Toplam & 94 & 100 \\
\hline
\end{tabular}

Korpus kallosum çevresinin konturlarının çizilip tamamının içine alındığı ROI ile elde edilen ADC değerleri (ROIADC), rostrum (ROSTADC), genu (GENUADC), korpus (KORPADC) ve spleniumdaki (SPLADC) ADC değerleri ölçüldü (Tablo 2). Tüm hastalar için, ROIADC değeri $0.735 \pm 0.043 \mathrm{~mm}^{2} / \mathrm{sn} x$ $10^{-3}$ olarak bulundu.

Korpus kallosum bölümlerinden ölçülen ADC değerlerinin birbiriyle ilişkisi ve bu bölgelerin her birindeki ADC ölçümleri ile ilerleyen yaş arasında fark olup olmadığı değerlendirildi (Tablo 3). Pearson katsayısı kullanarak yapılan korelasyon testinde, korpus kallosumun ortalama ADC değeri ile rostrum ( $\mathrm{r}$ $=.24, \mathrm{p}<0.05)$, genu $(\mathrm{r}=.23, \mathrm{p}<0.05)$ ve spleniumun ADC değerleri $(r=.37, p<0.05)$ arasında zayıf korelasyon saptand1. Yani korpus hariç diğer korpus kallosum bölümlerinin $\mathrm{ADC}$ değerleri, korpus kallosumun ortalama ADC değeri ile paralellik sergiliyordu. Ayrıca rostrum ve genudan ölçülen ADC değerleri arasında da zayıf korelasyonu izlendi $(r=.30$, $\mathrm{p}<0.01)$

Tablo 2. Korpus kallosumun farklı bölümlerindeki ADC değerleri

\begin{tabular}{lccc}
\hline & $\begin{array}{c}\text { Ortalama } \\
\mathrm{mm}^{2} / \mathrm{sn} \times 10^{-3} \pm \mathrm{SD}\end{array}$ & $\begin{array}{c}\text { Minimum } \\
\mathrm{mm}^{2} / \mathrm{sn} \times 10^{-3}\end{array}$ & $\mathrm{~mm}^{2} / \mathrm{sn} \times 10^{-3}$ \\
\hline ROIADC & $735 \pm 43$ & 589 & 819 \\
ROSTADC & $770 \pm 84$ & 568 & 924 \\
GENUADC & $772 \pm 68$ & 621 & 936 \\
KORPADC & $715 \pm 67$ & 530 & 839 \\
SPLADC & $724 \pm 73$ & 532 & 872 \\
\hline
\end{tabular}

Tablo 3: Korpus kallosumun tümü ile bölümlerindeki ADC değerlerinin karşılaştırılması

\begin{tabular}{lcccccc}
\hline & ROI & ROST & GENU & KORP & SPL \\
& ADC & ADC & ADC & ADC & ADC \\
& $\mathrm{p}$ & $\mathrm{p}$ & $\mathrm{p}$ & $\mathrm{p}$ & $\mathrm{p}$ \\
\hline ROIADC & - & $<0.05$ & $<0.05$ & 0.081 & $<0.001$ \\
ROSTADC & $<0.05$ & - & $<0.01$ & 0.073 & 0.557 \\
GENUADC & $<0.05$ & $<0.01$ & - & 0.068 & 0.258 \\
KORPADC & 0.081 & 0.073 & 0.068 & - & 0.086 \\
SPLADC & $<0.001$ & 0.552 & 0.258 & 0.086 & - \\
\hline
\end{tabular}

Yaş ve diğer değişkenler arasındaki ilişkiyi incelemek için Pearson korelasyon katsayısı hesaplandı. Yapılan değerlendirmelerde, korpus kallosumun tümünün ortalama ADC değeri ile artan yaş, istatistiksel olarak uyumlu bulundu $(\mathrm{r}=.277, \mathrm{p}<0.01)$. Ayrica genu ve spleniumdan ölçülen ADC değerleri ile de yaş arasında 
pozitif yönde ilişki tespit edildi. Yani yaş ilerledikçe korpus kallosumun ortalama ADC değeri arttığı gibi genu $(r=.208, p<0.05)$ ve spleniumun ADC değerleri de artış gösterdi $(\mathrm{r}=.213, \mathrm{p}<0.05)$, (Tablo 4).

Korpus kallosumun tümünün, rostrum, genu, korpus ve spleniumun ADC değerlerinde, yaş gruplarına göre fark olup olmadığı, One-Way ANOVA ile incelendi (Tablo 5).

Korpus kallosumun ortalama ADC değerleri, yaş grupları arasında istatistiksel açıdan belirgin fark göstermedi. Sadece korpusun ADC değerleri, yaş gruplarına göre istatistiksel açıdan farklıydı $(\mathrm{p}<0.05)$. Tukey testi ile yapılan ikili kaşılaştırmada hangi yaş grubu ya da gruplarının bu farklılığı oluşturduğu incelendi. Korpusun ADC değerleri açısından; 19 yaş altı ile 40 - 49 yaş grubu arasında fark bulunduğu $\operatorname{saptand}_{1}(\mathrm{p}<0.05)$.

\section{Yaş gruplart}

Korpus kallosumun ortalama ADC değeri, 60 yaş altında $0.730 \pm 0.44 \mathrm{~mm}^{2} / \mathrm{sn}, 60$ yaş üzerinde $0.758 \pm$
$0.26 \mathrm{~mm}^{2} / \mathrm{sn} \times 10^{-3}$ olarak bulundu. Bu iki grup arasında ADC değerleri, istatistiksel açıdan farklı olup 60 yaş üzerinde belirgin artış gösterdi ( $p<0.05$; Tablo 6). Yapilan t testi sonucunda, korpus kallosumun ADC değerlerinde, kadın ve erkek cinsiyetleri arasında, istatistiksel açıdan anlamlı bir farklılık izlenmedi (Tablo 7).

Tablo 4: Korpus kallosumun bölümlerinin, ADC değerlerinin yaş ile korelasyonu

\begin{tabular}{lcc}
\hline & $\begin{array}{c}\text { r değeri } \\
\text { (Pearson korelasyon) }\end{array}$ & p değeri \\
\hline ROIADC & .277 & $<0.01$ \\
ROSTADC & .080 & .442 \\
GENUADC & .208 & $<0.05$ \\
KORPADC & .120 & .250 \\
SPLADC & .213 & $<0.05$
\end{tabular}

Tablo 5: Yaş gruplarına göre korpus kallosumun tümü ile farklı kesimlerinin ortalama ADC değerleri. Ortalama ADC değerleri, $\left(\mathrm{mm}^{2} / \mathrm{snx} 10^{-3}\right) \pm$ standart deviasyon (SD)

\begin{tabular}{lccccc}
\hline Yaş & Ortalama & Ortalama & Ortalama & Ortalama & Ortalama \\
& ROIADC & ROSTADC & GENUADC & KORPADC & SPLADC \\
\hline$<=19$ & $722 \pm 42$ & $783 \pm 69$ & $737 \pm 43$ & $667 \pm 61$ & $699 \pm 39$ \\
$20-29$ & $726 \pm 44$ & $748 \pm 96$ & $749 \pm 76$ & $704 \pm 75$ & $686 \pm 90$ \\
$30-39$ & $725 \pm 44$ & $774 \pm 83$ & $762 \pm 70$ & $707 \pm 66$ & $732 \pm 75$ \\
$40-49$ & $734 \pm 50$ & $742 \pm 85$ & $792 \pm 74$ & $753 \pm 47$ & $733 \pm 70$ \\
$50-59$ & $784 \pm 84$ & $779 \pm 72$ & $718 \pm 68$ & $723 \pm 70$ \\
$60-69$ & $732 \pm 41$ & $800 \pm 51$ & $785 \pm 59$ & $730 \pm 57$ & $750 \pm 78$ \\
$70-79$ & $756 \pm 26$ & $762 \pm 115$ & $781 \pm 56$ & $683 \pm 75$ & $748 \pm 69$ \\
\hline Toplam & $766 \pm 30$ & $770 \pm 84$ & $772 \pm 68$ & $715 \pm 67$ & $724 \pm 73$ \\
\hline
\end{tabular}


Tablo 6: 60 yaş altı ve üzerindeki ADC değerleri

\begin{tabular}{lccc}
\hline Yaş & & $\begin{array}{c}\text { Ortalama } \\
\left(\mathrm{mm}^{2} / \mathrm{sn} \times 10^{-3} \pm \mathrm{SD}\right)\end{array}$ & $\begin{array}{c}\mathrm{p} \\
\text { değeri }\end{array}$ \\
& $>60$ & $730 \pm 44$ & 0.002 \\
\hline ROIADC & $<=60$ & $767 \pm 84$ & 0.489 \\
ROSTADC $<=60$ & $784 \pm 86$ & \\
& $>60$ & $771 \pm 71$ & 0.762 \\
GENUADC $<=60$ & $777 \pm 56$ & \\
KORPADC $<=60$ & $718 \pm 67$ & 0.460 \\
& $>60$ & $704 \pm 68$ & \\
SPLADC $<=60$ & $721 \pm 73$ & 0.313 \\
& $>60$ & $742 \pm 73$ & \\
\hline
\end{tabular}

Tablo 7: Cinsiyet gruplarına göre ortalama ADC değerlerindeki farklılıklar

\begin{tabular}{lccc}
\hline & Cins & Ortalama ADC & $\mathrm{p}$ \\
& $\mathrm{n}=95$ & $\begin{array}{c}\left.\text { (mm²/snx } 10^{-3} \pm \mathrm{SD}\right) \\
\text { değeri }\end{array}$ & \\
\hline ROIADC & Kadın & $733 \pm 42$ & .643 \\
& Erkek & $737 \pm 44$ & \\
ROSTADC & Kadın & $777 \pm 78$ & .313 \\
& Erkek & $759 \pm 92$ & \\
GENUADC & Kadın & $773 \pm 71$ & .833 \\
& Erkek & $770 \pm 65$ & \\
KORPADC & Kadın & $713 \pm 66$ & .623 \\
& Erkek & $720 \pm 69$ & \\
& Kadın & $734 \pm 67$ & .092 \\
SPLADC & Erkek & $708 \pm 80$ & \\
& & &
\end{tabular}

Korpus kallosum uzunluğunun, yani anteroposterior boyutunun ortalama değeri $69.37 \pm 4 \mathrm{~mm}$ olarak bulundu. Bu uzunluğun erkeklerde kadınlara göre daha fazla olduğu saptandı $(\mathrm{p}<0.05)$. Ayrıca yaş gruplarına göre yapılan analizde 20 - 29 yaş grubu ve 19 yaş altındaki olgularla, 70 yaş üzerindeki olgular arasında korpus kallosum boyu açısından istatistiksel açıdan anlam taşıyan farklılık saptand $1(\mathrm{p}<0.05)$ ve yaş ilerledikçe korpus kallosum uzunluğunun $\operatorname{arttığ1}$ sonucuna varıldı. Ancak korpus kallosum ile ilgili yapılan korpus, genu, splenium boyut ve korpus kallosum yüzey ölçüm değerleri ile yaş ve cinsiyet grupları arasında anlamlı ilişki saptanmadı.

\section{TARTIŞMA}

Son 20 yılda MRG, nörolojik hastalıkların değerlendirilmesinde dramatik değişikliklere imkan vermiştir (6). Kantitatif değerlendirme sağlayan ADC değerlerinin ölçülebilir hale gelmesi difüzyon ağırlıklı görüntülemeyi tanı ve ayırıcı tanının önemli bir silahı haline getirmiştir. Difüzyon ağırlıklı görüntülerin ortalama 22 saniye gibi kısa bir sürede elde olunabilmesi tekniği daha da değerli k1lmaktadır. İncelenen dokunun difüzyon değerlerinin ADC haritaları üzerinden ölçülüp sayısal olarak değerlendirilebilir olması difüzyon ağırlıklı görüntülemenin diğer avantajlarındandır (7).

Difüzyon karakteristikleri, beyinde yapısal ve dinamik (enerji metabolizması) özellikleri yansıtmaktadır. Yaşlanmayla yapısal değişiklikler ilişkili olduğu için suyun difüzyon kabiliyetinin yaş gruplarında bu farklılıkları yansıtacak şekilde değişebileceği düşünülmektedir (8). Çalışmamızda korpus kallosum ADC değerlerinin elde edilmesi, bu değerlerin başta yaş olmak üzere cinsiyet, boyut ve korpus kallosumun farklı bölümlerindeki ölçümlerle karşılaştırılması amaçlanmıştır. Sonuçta, vakalarımız için, korpus kallosumun, ortalama ADC değeri $0.735 \pm 0.043 \mathrm{~mm}^{2} /$ sn $\times 10^{-3}$ olarak bulunmuştur. Şener ve arkadaşlarının korpus kallosum için buldukları değer $0.75 \pm 0.15 \mathrm{~mm}^{2}$ / sn $\times 10^{-3}$ olup, Tanner ve arkadaşlarının yaptığ çalışmada, spleniumda, ortalama difüzyon değeri prematür yeni doğanda $1.43 \mathrm{~mm}^{2} / \mathrm{sn} \times 10^{-3}$, erişkinde ise $0.75 \mathrm{~mm}^{2} / \mathrm{sn} \times 10^{-3}$ olarak bulunmuştur $(9,10)$. Ray ve arkadaşları hafif kognitif bozukluğu olan hastalarla yaptıkları araştırmada korpus kallosumun ADC değerlerini hastalarda $1.098 \mathrm{~mm}^{2} / \mathrm{sn} \times 10^{-3}$, aynı yaş grubundaki kontrol grubunda $0.890 \mathrm{~mm}^{2} / \mathrm{sn} \times 10^{-3}$ 
olarak bulmuşlardır (11). Ray ve arkadaşlarının kontrol grubundaki değerler çalışmamızdaki değerlere göre daha yüksektir. Ancak Ray ve arkadaşlarının çalışmasındaki yaş ortalaması hastalarda 74, sağlıklı control deneklerde ise 75'tir. ADC değerlerindeki bu farklılıkların, yaş grbundaki farklılıktan ve farklı b değeri gibi parametrelerden de kaynaklanabileceği göz önünde bulundurulmalıdır.

Yaptığımız araştırma sonucunda, Pearson korelasyon katsayısı hesaplanarak yaş ve diğer değişkenler arasındaki ilişkiyi incelemek için yapılan değerlendirmelerde, yaş arttıkça, korpus kallosumun ortalama ADC değerlerinde, istatistiksel olarak belirgin derecede artış bulunmuş $(\mathrm{p}<0.01)$ ve suyun difüzyon kabiliyetinin korpus kallosumda yaş ilerledikçe arttığ1 sonucuna varılmıştır. Yani, ilerleyen yaşla beyaz cevherdeki suyun difüzyon kabiliyetindeki artış yönündeki teorimiz, verilerimizdeki istatistiksel olarak anlamlı sonuçlarla desteklenmiştir.

Korpus kallosumun bölümlerinin de yaşla ilişkili difüzyon farklılıklarının değerlendirilmesi araştırmamızın bir parçasını oluşturmaktadır. Korpus kallosumun bölümlerine yönelik yaptığımız incelemede, yaş ile genu ve spleniumdan ölçülen ADC değerleri arasında da pozitif yönde ilişki tespit edilmiştir ( $p<0.05)$. Sonuçta, yaş ilerledikçe, korpus kallosumun ortalama ADC değerleri ile genu ve spleniumundan ölçülen ADC değerlerinin arttığı ortaya konmuştur. Gideon ve arkadaşları yaşlanmayla subkortikal beyaz cevherde bir çok lokalizasyonda belirgin ADC artışını saptamışlar; ancak çalışmalarında korpus kallosumdaki ADC değerlerinde yaş ile bir değişiklik izlememişlerdir (2). Bilgili ve arkadaşları ise, beyinde gerek beyaz cevher gerekse de gri cevherde ilerleyen yaşla ölçülen ADC değerlerindeki artışın beyaz cevherde istatistiksel olarak anlamlı farklılığa neden olduğunu, gri cevherde ise anlamlı farklılığa neden olmadığını saptamışlardır (1).

Çalışmamızda, en yüksek ortalama difüzyon katsayısının perivenriküler beyaz cevherde olduğu bildirilmiştir. $\mathrm{Bu}$ durumun, BOS içeren ventriküllerin ROI’ye yakınlığından kaynaklanabileceği ihtimali nedeniyle, Zhang ve arkadaşlarının da önerdiği gibi daha büyük örnekleme alanının korpus kallosumun difüzyon özelliklerini belirlemek açısından daha yararlı olacağı göz önünde bulundurulabilir (4).

Araştırmamızda, dekadlara göre sınıflandırdığımız bireylerde, korpus kallosumun ortalama ADC değerleri, rostrum, genu, korpus ve spleniumun ADC değerleri ile yaş grupları arasında fark olup olmadığı, tek yönlü varyans analizi ile incelendi. Korpus kallosumun ortalama ADC değerleri açısından, dekadlara ayrılan yaş grupları arasında istatistiksel açıdan belirgin fark saptanmadı. Korpus kallosumun sadece korpus bölümünün $\mathrm{ADC}$ değerleri, yaş gruplarına göre, istatistiksel olarak farklıydı $(\mathrm{p}<0.05)$. Hangi yaş grubu ya da gruplarının farklılığı yarattığı Tukey testi ile, ikili kaşılaştırmalarla incelendi. Korpusun ADC değerleri için yapilan bu değerlendirmede 19 yaş altı ile karşılaştırıldığında 40 49 yaş grubunun ADC değerlerindeki farkın en belirgin olduğu saptandı $(\mathrm{p}<0.05)$. Bunun dışında çalışma grubu 60 yaş ve altı ile 60 yaş üzeri olarak da ayrıldı. Korpus kallosumun ortalama ADC değeri, çalışmamızda, 60 yaş altında $0.730 \pm 0.44 \mathrm{~mm}^{2} / \mathrm{sn} x$ $10^{-3}, 60$ yaş üzerinde $0.758 \pm 0.26 \mathrm{~mm}^{2} / \mathrm{sn} \times 10^{-3}$ olarak bulundu. Bu iki grup arasındaki ADC değerleri, istatistiksel açıdan farklı olup 60 yaş üzerinde, ADC değerleri belirgin artış göstermekteydi $(p<0.05)$. İnsanda subkortikal beyaz cevherde çoğu akson myelinedir (8). Yaşlanmanın etkisiyle oluşan, difüzyondaki artış, subkortikal beyaz cevherde myeline fibrillerdeki azalma ya da artmış su içeriğinden kaynaklanabilir (12). Myelin tabakaların azalan stabilitesi nedeniyle suyun difüzyon kabiliyeti kolaylaşmaktadır (8). Huttenlocher ve arkadaşları yaptıkları araştırmada sinaptik dansitenin 72 yaş sonrasında azaldığı saptamış olup, su moleküllerinin difüzyonunun kısıtlanmasında azalmanın bu etkiden sorumlu olabileceğini belirtmişlerdir (1). Chun ve arkadaşları beyinde yaşa bağlı oluşan değişikliklerin, 60 yaş üzerinde en belirgin olduğunu saptamışlardır (12). Çalışmamızda 60 yaş ve üzeri bireylerde ADC değerleri 60 yaş altındakilere göre istatistiksel açıdan 
belirgin olarak artış göstermiştir. Engelter ve arkadaşlarının verileri de bu yaş grubu için moleküler difüzyonda artış olduğunu desteklemiştir (8 Yaşlanma sürecinde, beyaz cevherin total hacminde azalmanın ortaya çıktığı gerek otopsi gerekse de MRG sonuçları ile bilinmektedir (1). Ayrica otopsi serilerinde 50 yaşına kadar myelin içeriğinin stabil kaldığı, sekizinci dekada kadar myeline liflerde \%10- 15 azalma olduğu saptanmıştır (8).

Yapılan korelasyon testinde, korpus kallosumun tümünün ortalama $\mathrm{ADC}$ değerleri ile rostrum $(\mathrm{p}<$ 0.05), genu $(\mathrm{p}<0.05)$ ve spleniumun ADC değerleri ( $\mathrm{p}$ $<0.05$ ) arasında korelasyon saptanmıştır. Yani korpus hariç diğer korpus kallosum bölümlerinin $\mathrm{ADC}$ değerleri, korpus kallosumun ortalama ADC değeri ile paralellik sergiliyordu. Daha önce erişkinlerde yapılan bazı çalışmalarda spleniumun, korpus kallosumun geri kalanına göre daha yüksek anisotropi ve ortalama difüzyon katsayısına sahip olduğu gösterilmiştir (4). Santos ve arkadaşlarının çalışmalarında korpus kallosum genu ve spleniumundaki ADC değerleri, istatistiksel açıdan anlamlı olarak farklılık göstermiştir. Korpus kallosumda genu ince, zayıf myelinize fibrillerden, splenium ise daha kalın fibrillerden oluşmaktadır. Yani splenium daha geniş intrasellüler, daha dar ekstrasellüler hacime sahiptir. Dolayısıyla bu iki bölüm arasındaki farklı yapılanma farklı sinyal değişikliklerini açıklamaktadır. Fibril dansitesi myelinasyon derecesi, ekstrasellüler alanın durumu ve muhtemelen membranla ilişkili farklılıklar difüzyon sinyalinin belirlenmesinde etkilidir (13).

Difüzyon değerlerinin yanı sıra korpus kallosum boyutları ve yüzeyinin de ölçüldüğü araştırmamızda, korpus kallosum uzunluğunun, yani anteroposterior boyutunun ortalama değeri $69.37 \pm 4 \mathrm{~mm}$ olarak bulunmuştur. $\mathrm{Bu}$ uzunluğun erkeklerde kadınlara göre daha fazla olduğu istatistiksel olarak belirlenmiştir $(\mathrm{p}<$ 0.05). Ayrıca yaş gruplarına göre yapılan analizde 30 yaş altındaki olgularla, 70 yaş üzerindeki olgular arasında korpus kallosum boyu arasında istatistiksel açıdan anlam taşıyan farklılık saptanmıştır $(\mathrm{p}<0.05)$. Ancak araştırmamızda, korpus, genu, splenium boyut ve korpus kallosum yüzey ölçüm değerleri ile yaş ve cinsiyet grupları arasında anlamlı fark saptanmamıştır. Literatürde cinsiyet farkları arasında serebral yapılar ve fonksiyonlarla ilgili farklı farklı sonuçlar elde edilmiştir (14). Bazı araştırmalarda cinsiyet farkıyla kallosal alan arasında bir bağlantı bulunamamış ancak bazılarında kalosal alanın erkeklerde ve ana konuşma merkezi sağda olanlarda daha geniş olduğu bildirilmiştir (15). Mesela Jänke ve arkadaşlarının çalışmasında korpus kallosumla ilgili cinsiyet farklılıkları araştırılmış ve kadın-erkek cinsiyetleri arasında kallozal alan farklılığı bulunmamıştır. Ancak bu çalışmada erkeklerin serebral hacminin kadınlardan fazla olduğu gösterilmiştir. Mitchell ve arkadaşlarının yaptığı çalışmada erkeklerin büyük beyin hacimlerine karşın küçük kallozal alana, kadınlarınsa küçük beyin hacimlerine karşın büyük kallozal alana sahip oldukları gösterilmiştir. Davatzikos ve Resnick, erkeklerde kallozal alanın daha geniş olduğunu göstermişlerdir (14). Yine bazı çalışmalarda korpus kallosum alanının erkeklerde, kadınlardan fazla olduğu (15) bazılarında ise splenium boyutunun kadında fazla olduğu ve şeklinin daha bulboz göründüğü bildirilmektedir (16). Korpus kallosumun, yaşa göre değerlendirilmesi amacıyla yaptığımız bu çalışmada, sonuçlarımız, yaş arttıkça, korpus kallosumun ortalama ADC değerlerinde istatistiksel olarak belirgin derecede artış olduğunu göstermiştir ( $\mathrm{p}<0.01)$. Ayrıca ilerleyen yaşla genu ve spleniumdan ölçülen ADC değerleri arasında da pozitif yönde ilişki tespit edilmiştir $(p<0.05)$. Çalışmamızda korpus kallosumun tümünü, BOS kontaminasyonundan koruyacak şekilde ROI içine alarak elde ettiğimiz ortalama ADC değerlerinin, tek tek, farklı bölümlerde ölçülen ADC değerlerine göre daha tutarlı ve literatürle uyumlu sonuçlar vermesi en dikkat çekici noktalardan biri olmuştur. Korpus kallosumun tarif edilen yöntemle elde edilen ortalama ADC değerinin, artan yaşla belirgin korelasyon göstermesi, ADC değerinin bu yöntemle daha sağlıklı olarak alınabileceğini ve bu ölçümlerin rutin MRG'nin bir parçası olabileceğini göstermiştir.

Çalışmamızın en önemli limitasyonu, yukarıda 
belirtildiği gibi, korpus kallosumun kalınlığının az ve BOS'a çok yakın bir yapı olması ve bu nedenle BOS kontaminasyonundan kaçınmak için ROI'nin küçük $\left(10 \pm 2 \mathrm{~mm}^{2}\right)$ olarak seçilmesinin zorunlu olmasıydı. Ancak kü̧̈ük ROI kullanımı sırasında rastlanan artefaktların ölçümlerde etkilerinin daha fazla olması nedeniyle, korpus kallosumun çevresi çizilerek oluşturulan, ROI ile elde edilen sonuçların daha sağlıklı olduğu sonucuna varılmıştır.

Sonuç olarak, sağlıklı olgularda, farklı yaş gruplarında, korpus kallosuma ait ADC değerleri, geniş bir populasyonda tespit edilmiştir. $\mathrm{Bu}$ veriler, korpus kallosumu sıklıkla tutan pek çok hastalığın, ADC değerleri üzerindeki etkilerinin tespitinde, veri tabanı oluşturabilecektir. ADC değerlerinin, bazı hastalıkların erken tanısında, kolaylık sağlayacağı ve daha sık kullanılması gerektiği inancındayız.

\section{KAYNAKLAR}

1. Bilgili $Y$, Ünal B, Kendi $T$, Simsir İ, Erdal H, Huvaj S ve ark. MRG ile normal görünümlü beyaz ve gri cevherde yaşlanmanın etkilerinin ADC değerleri ile saptanabilirliği. Tanısal ve Girişimsel Radyoloji. 2004;10(1):4-7.

2. Nusbaum AO, Tang CY, Buchsbaum MS, Wei TC, Atlas SW. Regional and global changes in cerebral diffusion with normal aging. Am J Neuroradiol January. 2001;22:136-42.

3. Barkovich AJ. Pediatric neuroimaging. 2nd Ed. New York, Raven Press Ltd, 1995.

4. Zhang L, Thomas KM, Davidson MC, Casey BJ, Heier LA, Uluğ AM. MR quantitation of volume and diffusion changes in the developing brain. AJNR. 2005;26:45-9.

5. Wimberger DM, Roberts TP, Barkovich AJ, Prayer LM, Moseley ME. Identification of promyelination by diffusion weighted MRI. J Comput Assist Tomogr. 1995;19:28-33.

6. Grossman RI, McGowan JC. Perspectives on multiple sclerosis. AJNR. 1998;19:1251-65.

7. Şener RN. Difüzyon MRG'de "Apparent Diffusion Coefficient" (ADC) değerleri. Tanısal ve Girişimsel
Radyoloji. 2001;7:460-3.

8. Engelter ST, Provenzale JM, Petrella JR, DeLong DM, MacFall JR. The effect of aging on the apparent diffusion coefficient of normal-appearing white matter. AJR. 2000;175:425-30.

9. Sener RN. Diffusion MRI: Apparent Diffusion Coefficient (ADC) values in the normal brain and classificiation of brain disorders based on ADC Values. Computerized Medical Imaging and Graphics. 2001;25:299-326.

10. Tanner SF, Ramenghi LA, Ridgway JP, Berry E, Saysell MA. Quantitative comparison of intrabrain diffusion in adults and preterm and term neonates and infants. AJR. 2000;174:1643-9.

11. Ray KM, Wang H, Chu Y, Chen YF, Bert A, Hasso $\mathrm{AN}$, et al. Mild cognitive impairment: apparent diffusion coefficient in regional gray matter and white matter structures. Radiology. 2006;241:197205

12. Chun T, Filippi CG, Zimmerman RD, Ulug AM. Diffusion changes in the aging human brain. AJNR. 2000;21:1078-83.

13. Santos JMG, Ordóñez C, Torres del Rio S. ADC measurements at low and high $\mathrm{b}$ values: insight into normal brain structure with clinical DWI. Magn Reson Imaging. 2008;26:35-44.

14. Bozzao A, Floris R, Baviera ME, Apruzzese A, Simonetti G. Diffusion and perfusion mr imaging in cases of alzheimer's disease: correlations with cortical atrophy and lesion load. AJNR. 2001;22:1030-6.

15. Mitchell TN, Samantha LF, Merschhemke M. Reliable callosal measurement: population normative data confirm sex-related differences. AJNR. 2003;24:410-8.

16. Reinarz JS, Coffman CE, Smoker WAK, Godersky JC. MR imaging of the corpus callosum: normal and pathologic findings and correlation with CT. AJR. 1988;151:791-8. 